EXTENDED REPORT

\title{
Renal clearance and daily excretion of cortisol and adrenal androgens in patients with rheumatoid arthritis and systemic lupus erythematosus
}

\author{
R H Straub, C Weidler, B Demmel, M Herrmann, F Kees, M Schmidt, J Schölmerich, J Schedel
}

Ann Rheum Dis 2004;63:961-968. doi: 10.1136/ard.2003.014274

See end of article for authors' affiliations

Correspondence to:

Professor R H Straub, Laboratory of

Neuroendocrinoimmuno-

logy, Department of

Internal Medicine I,

University Hospital

Regensburg, D-93042

Regensburg, Germany;

rainer.straub@klinik.

uni-regensburg.de

Accepted

28 September 2003

\begin{abstract}
Background: In rheumatoid arthritis (RA) and systemic lupus erythematosus (SLE), patients demonstrate low levels of adrenal hormones.

Objective: To investigate whether increased renal clearance and daily excretion contribute to this phenomenon.

Methods: Thirty patients with RA, 32 with SLE, and 54 healthy subjects (HS) participated. Serum and urinary levels of cortisol, cortisone, 17-hydroxyprogesterone (17OHP), androstenedione, dehydroepiandrosterone (DHEA), and DHEA sulphate (DHEAS) were measured.

Results: Clearance of DHEAS and DHEA was lower in patients than in HS, and clearance of androstenedione was somewhat higher in patients than in $\mathrm{HS}$, but daily excretion of this latter hormone was low. Clearance of cortisol, cortisone, and 17OHP was similar between the groups. The total molar amount per hour of excreted DHEA, DHEAS, and androstenedione was lower in patients than HS (but similar for cortisol). Serum DHEAS levels correlated with urinary DHEAS levels in HS and patients, whereby HS excreted 5-10 times more of this hormone than excreted by patients. Low serum levels of adrenal androgens and cortisol in patients as compared with HS were confirmed, and proteinuria was not associated with changes of measured renal parameters.

Conclusions: This study in patients with RA and SLE demonstrates that low serum levels of adrenal androgens and cortisol are not due to increased renal clearance and daily loss of these hormones. Decreased adrenal production or increased conversion or conjugation to downstream hormones are the most likely causes of inadequately low serum levels of adrenal hormones in RA and SLE.
\end{abstract}

1 chronic inflammatory diseases, cortisol is reduced relative to the degree of systemic inflammation, as exemplified in African trypanosomiasis, ${ }^{1}$ Sjögren's syndrome, ${ }^{2}$ and systemic lupus erythematosus (SLE). ${ }^{3}$ This is particularly the case when the disease persists over a long period of time (over weeks). In rheumatoid arthritis (RA), it has been shown that patients have inappropriately low spontaneous and stimulated cortisol secretion in relation to systemic inflammation. ${ }^{4-13}$ Another significant finding in patients with RA and SLE is that serum levels of dehydroepiandrosterone sulphate (DHEAS) and other adrenal hormones are decreased. ${ }^{14-22}$ In RA, we have recently discussed how an alteration of the hypothalamus-pituitary-adrenal axis has an impact on perpetuation of the disease. ${ }^{23}$ Inadequately low serum levels of cortisol and significantly lower levels of adrenal androgens are thought to have a proinflammatory role. $^{23}$ This is most obvious for cortisol and DHEAS, which has been proved to be a therapeutic alternative in SLE and chronic inflammatory bowel diseases. ${ }^{24-27}$ However, it is still unclear whether increased renal clearance or daily loss of adrenal steroid hormones are significant factors for low serum hormone levels in chronic inflammatory diseases. Although the pioneering work of Masi et al demonstrated that urinary conversion products of adrenal androgens are significantly low in eight women with RA, these authors did not study renal clearance, and DHEAS and androstenedione were not included in their investigations. ${ }^{15}$ Furthermore, in their study the number of patients was small, only women participated, and the menstrual cycle was not reported. ${ }^{15}$

In this prospective study we aimed to investigate renal clearance and excretion of the major steroid hormones in patients with RA and SLE and to compare the results with those of healthy control subjects (HS) matched for age and sex. Because we wanted to determine the clearance of these hormones, it was necessary to measure the unconjugated and untransformed hormone of interest in the blood and in the urine. The data of patients of both disease groups are presented with and without prednisolone treatment. Because adrenal hormones were not markedly different in women and men, data were presented irrespective of sex.

\section{SUBJECTS AND METHODS}

\section{Patients and healthy control subjects}

Thirty white patients with diagnosed RA fulfilling the American College of Rheumatology (ACR) criteria were included.$^{28}$ Clinical variables of disease activity included the number of swollen and tender joints and erythrocyte sedimentation rate. To study simultaneously patients with another chronic inflammatory disease, we enrolled 32 white patients with SLE according to the criteria of the ACR. ${ }^{29}$ In these latter patients, clinical activity was assessed by the SLE Disease Activity Index (SLEDAI). Table 1 shows the basic characteristics of both disease groups. Clearly, the patients in both disease groups had mild to moderate disease activity. Because prednisolone treatment influences production of adrenal hormones, data are given with and without prior

Abbreviations: $\mathrm{ACTH}$, adrenocorticotrophic hormone; $\mathrm{ACR}$, American College of Rheumatology; DHEA, dehydroepiandrosterone; DHEAS, DHEA sulphate; HPLC, high performance liquid chromatography; HS, healthy control subjects; IL, interleukin; RA, rheumatoid arthritis; 17OHP, 17-hydroxyprogesterone; SLE, systemic lupus erythematosus; TNF, tumour necrosis factor 
prednisolone treatment (see table 1 and "Results"). Because long term disease and treatment with non-steroidal antiinflammatory drugs or disease modifying antirheumatic drugs may influence renal function, we determined the type of proteinuria and creatinine clearance in order to control for possible kidney damage. Owing to a very different mean age in the two patient groups, patients with RA and SLE should not be directly compared (table 1 ).

For comparison, 54 white HS were recruited (mean (SEM) age 40.8 (1.5) years), and health status was verified by a 33 item questionnaire, as previously described. ${ }^{30}$ The questionnaire addressed known diseases in the past and present, current symptoms of diseases, current drugs, alcohol intake, smoking habits, family history, and surgical history. The questionnaire was adapted to the SENIEUR protocol. ${ }^{31}$ Our

Table 1 Basic characteristics of patients and healthy controls. Values demonstrate data of patients with and without prior prednisolone treatment. Data of healthy controls were not stratified because the entire group matched in age and sex to the respective patient subgroup

\begin{tabular}{ll}
\multicolumn{2}{l}{ Rheumatoid arthritis } \\
\hline $\begin{array}{ll}\text { With prior } & \text { Without prior } \\
\text { prednisolone } & \text { prednisolone } \\
\text { treatment } & \text { treatment }\end{array}$
\end{tabular}
Healthy Comparison of patients with RA and healthy subjects (age/sex matched) Number Age (years) Sex (F/M) Disease duration (years) Number of swollen joints Number of painful joints $\operatorname{ESR}(\mathrm{mm} / 1 \mathrm{st}$ h) Drugs Prednisolone Prednisolone (mg/day) Methotrexate NSAIDs Leflunomide Anti-TNF strategy Sulfasalazine Hydroxychloroquine Cyclophosphamide Azathioprine

20 58 (3) $13 / 7$ $12(2)$ $6(2)$ $8(2)$ 32 (4) 20 9 (3) 6 9 6 3 1 1 0

\begin{tabular}{lll}
\multicolumn{2}{l}{ Systemic lupus erythematosus } & \\
\cline { 1 - 2 } $\begin{array}{l}\text { With prior } \\
\text { prednisolone }\end{array}$ & $\begin{array}{l}\text { Without prior } \\
\text { prednisolone } \\
\text { treatment }\end{array}$ & $\begin{array}{l}\text { Healthy } \\
\text { treatment }\end{array}$ \\
\end{tabular}

Comparison of patients with SLE and healthy subjects (age/sex matched) Number Age (years) Sex (F/M) Disease duration (years) SLEDAI (points) $\operatorname{ESR}(\mathrm{mm} / 1 \mathrm{st} h)$ Drugs

Prednisolone 22 Prednisolone (mg/day) Methotrexate NSAIDs

Leflunomide Anti-TNF strategy Sulfasalazine Hydroxychloroquine Cyclophosphamide Azathioprine

$\begin{array}{lll}22 & 10 & 42 \\ 35(2) & 45(5) & 37(2) \\ 18 / 4 & 6 / 4 & 25 / 17 \\ 8(2) & 9(3) & \text { NA } \\ 11(2) & 11(2) & \text { NA } \\ 30(4) & 18(3) & \text { NM } \\ 22 & 0 & \text { NA } \\ 14(5) & 0(0) & \text { NA } \\ 1 & 0 & \text { NA } \\ 8 & 5 & \text { NA } \\ 0 & 0 & \text { NA } \\ \text { NA } & \text { NA } & \text { NA } \\ 0 & 0 & \text { NA } \\ 3 & 0 & \text { NA } \\ 1 & 0 & \text { NA } \\ 8 & 4 & \end{array}$

Anti-TNF strategies are either infliximab or etanercept. Prednisolone treatment was not interrupted during 24 hour collection of urine. Data are given as means (SEM) or as number of patients/controls. ESR, erythrocyte sedimentation rate; NA, not applicable; NM, not measured; NSAIDs, non-steroidal anti-inflammatory drugs; SLE, systemic lupus erythematosus; SLEDAl, SLE Disease Activity Index. protocol established strict admission criteria for immunogerontological studies in man based on clinical information. Fertile women (HS and patients) were not taking contraceptives and they were in the early to mid-follicular phase of the menstrual cycle as assessed by progesterone serum levels.

Owing to the different age and sex in the disease groups, subgroup analyses were carried out in order to compare correctly the different groups with HS. The subgroups were matched according to age and sex (table 1). Because serum levels of adrenal hormones are largely independent of sex, men and women were not further separated into subgroups.

Patients and HS were instructed to collect urine for 24 hours in special urine containers during the day before the visit. On the day of the visit, between 800 and $1000 \mathrm{am}$, serum, plasma, and urine for further determination of steroid hormones or creatinine were taken and stored at $-30^{\circ} \mathrm{C}$ in adequate aliquots. All patients and HS gave written consent for further investigation of samples. Owing to the difficulties in recruiting a large number of patients and HS (without contraceptives and in the correct phase of the menstrual cycle), collection of the material took 2 years.

\section{Laboratory parameters}

Several adrenal hormones were considered in order to detect major adrenal pathways of steroidogenesis. Figure 1 demonstrates the steroid cascades in the adrenal gland. We used a radioimmunometric assay for the quantitative determination of serum and urine levels of cortisol (Coulter Immunotech, Marseilles, France; detection limit $10 \mathrm{nmol} / \mathrm{l})$. Serum and urine levels of androstenedione (IBL, Hamburg, Germany; detection limit $0.15 \mathrm{nmol} / \mathrm{l}), 17$-hydroxyprogesterone (17OHP; IBL, Hamburg, Germany; detection limit $0.3 \mathrm{nmol} / \mathrm{l})$, DHEAS (IBL, Hamburg, Germany; detection limit $130 \mathrm{nmol} / \mathrm{l}$ ), and DHEA (Diagnostic Systems Laboratory, Webster, Texas; detection limit $0.13 \mathrm{nmol} / \mathrm{l}$ ) were measured by immunometric enzyme immunoassays. Plasma adrenocorticotrophic hormone (ACTH) was detected by enzyme immunoassay (Sangui BioTech, Inc, California, USA, via IBL, Hamburg, Germany; detection limit $0.1 \mathrm{pmol} / \mathrm{l}$ ). For all assays, intraassay and interassay coefficients of variation were below $10 \%$. Cross reactivities between measured hormone and prednisolone were as follows: for cortisol $\leqslant 6 \%$; cortisone $0 \%$; androstenedione $<1 \%$; $17 \mathrm{OHP}<0.1 \%$; DHEA $<0.1 \%$; and DHEAS $<0.1 \%$.

Creatinine in serum and urine was measured on an automated Hitachi analyser (Hitachi 917, Wiesbaden, Germany) using the CREA method (Roche Diagnostics, Mannheim, Germany), which is based on the Jaffé method. The assay has an intra- and interassay imprecision of $<0.7$ and $<3.7 \%$. To study urinary proteins we used an immunoprecipitation technique for the immunological, qualitative, and semiquantitative detection. ${ }^{32}$ This technique allows diagnosis of selective and non-selective glomerular proteinuria, tubular proteinuria, and mixed selective and nonselective glomerular plus tubular proteinuria.

\section{High performance liquid chromatographic determination of cortisone and prednisolone}

Cortisol, cortisone, and prednisolone were determined by high performance liquid chromatography (HPLC) with photometric detection at $245 \mathrm{~nm}$, adapting a published method. ${ }^{33}$ Briefly, $200 \mu \mathrm{l}$ serum or urine were mixed with $200 \mu \mathrm{l} 0.2 \mathrm{M}$ sodium hydrogen carbonate ( $\mathrm{pH}$ 9.6) and $25 \mu \mathrm{l}$ methylprednisolone (50 ng, internal standard solution), and extracted with $2 \mathrm{ml}$ dichloromethane. The organic layer was evaporated to dryness and the residue was reconstituted with $100 \mu \mathrm{l}$ mobile phase, of which $50 \mu \mathrm{l}$ was injected into the HPLC system. The chromatographic apparatus consisted of a solvent delivery system LC-10AS, autosampler SIL10A, 
ultraviolet detector SPD-10A, SCL-10 system controller, and class-LC10 integration software (Shimadzu, Duisburg, Germany). The analytes were separated using two analytical columns $(150 \times 4.6 \mathrm{~mm})$, a Synergi Polar-RP followed by a Synergi Max-RP (Phenomenex, Aschaffenburg, Germany), with water-acetonitrile $(70: 30, v / \mathrm{v})$ as mobile phase. Prednisolone eluted after 12.3 minutes, cortisol after 12.9 minutes, cortisone after 14.7 minutes, and methyl prednisolone (internal standard) after 19.1 minutes (flow rate $1.0 \mathrm{ml} / \mathrm{min}$, column temperature $40^{\circ} \mathrm{C}$ ). The recoveries of the analytes from serum or urine were $70-80 \%$, imprecision and bias were $<10 \%$. Calibration curves for peak heights versus quantity were linear up to about $2700 \mathrm{nmol} / \mathrm{l}$ prednisolone/cortisol and about $700 \mathrm{nmol} / \mathrm{l}$ prednisone/cortisone with coefficients of correlation $r_{\mathrm{s}}>0.996$. The minimal detectable amount injected ( signal/noise $=3 / 1$ ) was about $200 \mathrm{pg}$ of each analyte. The limit of measurement was estimated to be about $12 \mathrm{nmol} / \mathrm{l}$ for each compound. In some specimens an endogenous compound (equal to about $15 \mathrm{nmol} / \mathrm{l}$ prednisolone in serum and up to fivefold higher in urine) interfered with the determination of prednisolone. Patients with interferences were not included.

\section{Calculation of renal clearance}

Substance clearance was calculated according to the following formula:

\section{Clearance $=\mathrm{U} \times \mathrm{vol} / \mathrm{S} \times \mathrm{T}(\mathrm{ml} / \mathrm{min})$}

where $\mathrm{U}$ is the urinary substance concentration ( $\mathrm{nmol} / \mathrm{l})$, vol is the urinary collection volume $(\mathrm{ml}), \mathrm{S}$ is the serum substance concentration $(\mathrm{nmol} / \mathrm{l})$, and $\mathrm{T}$ is the collection time $(\mathrm{min})$. Because creatinine clearance was very similar in HS and patients (including subgroups), a mathematical adjustment of substance clearance using creatinine clearance was not necessary.

\section{Statistical analysis}

To compare medians in two different groups the MannWhitney signed rank test was used (SPSS/PC for Windows, version 10.0.5, SPSS, Inc, Chicago). Investigation of an interrelation between two variables was done using Spearman rank correlation analysis. In the figures, the linear regression line is given together with the Spearman rank correlation coefficient. Values of $\mathrm{p}<0.05$ were considered to be significant and results are given as means (SEM).

\section{RESULTS}

\section{Serum hormone concentrations}

In confirmation of previous studies, serum cortisol levels in the group of patients without corticosteroid treatment were lower (in SLE) or did not differ (in RA) from those in HS (figs 2A and D). This was similar for serum cortisone in both disease groups with prior prednisolone treatment (figs 2A and D). As expected, in patients with prednisolone pretreatment, serum levels of cortisol and cortisone were lower than in HS (figs 2A and D). As compared with HS, serum levels of DHEAS and androstenedione were lower in both disease groups, irrespective of prior prednisolone treatment (figs 2B, $\mathrm{E}$ and $2 \mathrm{C}, \mathrm{F})$. DHEA serum levels were near normal in RA and SLE without prednisolone treatment (figs 2C and F), and they were lower in both disease groups with prednisolone pretreatment (figs 2C and F). As compared with HS, the plasma levels of ACTH were significantly lower in prednisolone pretreated patients of both disease groups (RA+prednisolone $\quad v$ HS $2.6 \quad(0.3) \quad v \quad 7.8 \quad(2.4) \quad \mathrm{pmol} / \mathrm{l}$, $\mathrm{p}<0.00$ l; SLE+prednisolone $v$ HS 2.0 (0.2) v 4.9 (0.5) pmol/ $\mathrm{l}, \mathrm{p}<0.001)$, and ACTH plasma levels were lower in RA and similar in SLE without prednisolone treatment (RA without prednisolone $v$ HS 2.5 (0.4) $v 7.8(2.4) \mathrm{pmol} / \mathrm{l}, \mathrm{p}=0.001$; SLE without prednisolone $v$ HS $3.6(0.5) v 4.9$ (0.5) pmol/l, NS).

\section{Urinary hormone concentrations and daily hormone excretion}

If systemic steroid hormone loss is due to an increased renal excretion, one would expect increased urinary concentrations of these steroid hormones and increased molar amounts in the urine as compared with HS. Figures $3 \mathrm{~A}$ and D show that urinary concentration of cortisol was higher in patients with RA and tended to be higher in patients with SLE with prednisolone pretreatment than in HS. This was not the case for urinary cortisone, which was significantly lower in both patient groups with prednisolone pretreatment (figs $3 \mathrm{~A}$ and D). Average concentrations of all other steroid hormones tended to be lower or were significantly lower in both patient groups than in HS (fig 3). This was particularly true for urinary levels of DHEAS, DHEA, and androstenedione (fig 3). In a correlation analysis, it is obvious that serum and urinary

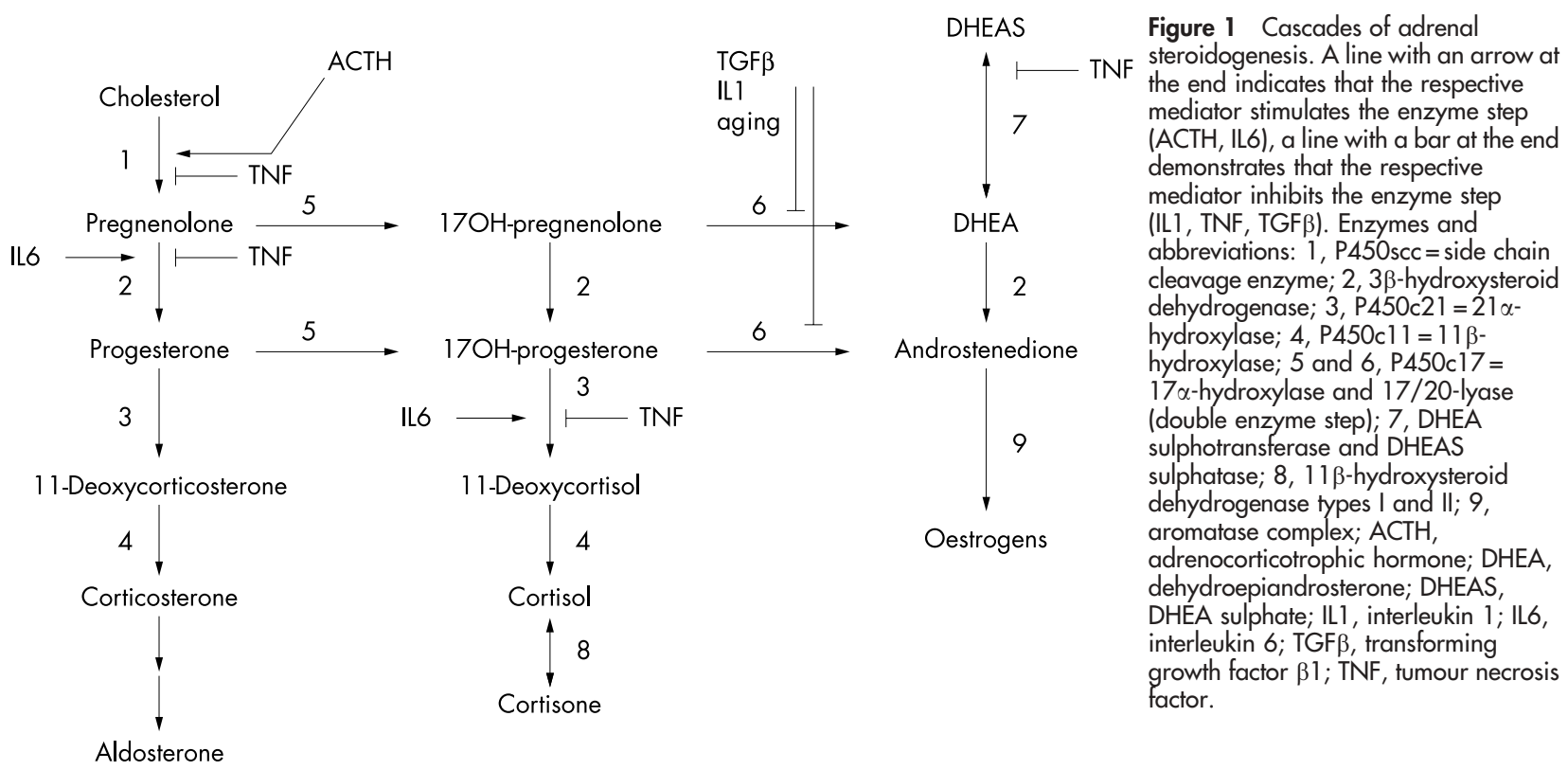


levels of DHEAS are significantly interrelated (fig 4). The slopes of the regression lines in fig 4 are very similar, which indicates that the excreted amount of DHEAS largely depends on the serum level of this hormone.

To estimate the relative contribution of each hormone to excretion of all hormones, the total excreted molar amount per day of each hormone was calculated (table 2). In both disease groups and HS, the total nanomolar amount per day of excreted DHEAS was about 10-2500 times higher than that of other steroid hormones (table 2). This reflects markedly higher serum levels of DHEAS than other steroid hormones (fig 2). Thus, DHEAS is the most important excreted adrenal hormone. In both disease groups, irrespective of prednisolone pretreatment, the total nanomolar amounts per day of excreted DHEA and DHEAS were markedly lower than those for HS (table 2). As compared with HS, the nanomolar amount of excreted cortisol per day was increased in RA with prednisolone pretreatment and tended to be increased in SLE with prednisolone pretreatment (table 2). Because the radioimmunoassay for cortisol measurement detects $6 \%$ of excreted prednisolone (cross reactivity $=6 \%$, see "Subjects and methods"), we attempted to estimate the contribution of excreted prednisolone to the measurement of cortisol. In patients with RA and SLE, including prednisolone pretreated patients, urine levels of cortisol highly significantly correlated with urine levels of prednisolone (RA: $R_{\text {Rank }}=0.885, p<0.001$; SLE: $\mathrm{R}_{\text {Rank }}=0.885, \mathrm{p}<0.001$ ). Patients with RA and SLE, including those with prednisolone treatment, excreted 2256 and $2040 \mathrm{nmol}$ prednisolone per day, respectively (6\% are 135 and $122 \mathrm{nmol} /$ day, respectively). Thus, it is likely that prednisolone contributes to the increased urinary cortisol concentration and total molar amount in both disease groups with prednisolone treatment (not for cortisone).

\section{Urinary substance clearance}

Renal clearance of a substance is the plasma volume per time which is totally cleared from the respective substance (in ml/ $\min$ ). Figure 5 shows that for creatinine, the creatinine cleared plasma volume per minute is about $100 \mathrm{ml}$. This value is markedly lower for steroid hormones (fig 5 ). In both disease groups, clearance of DHEAS and DHEA tended to be
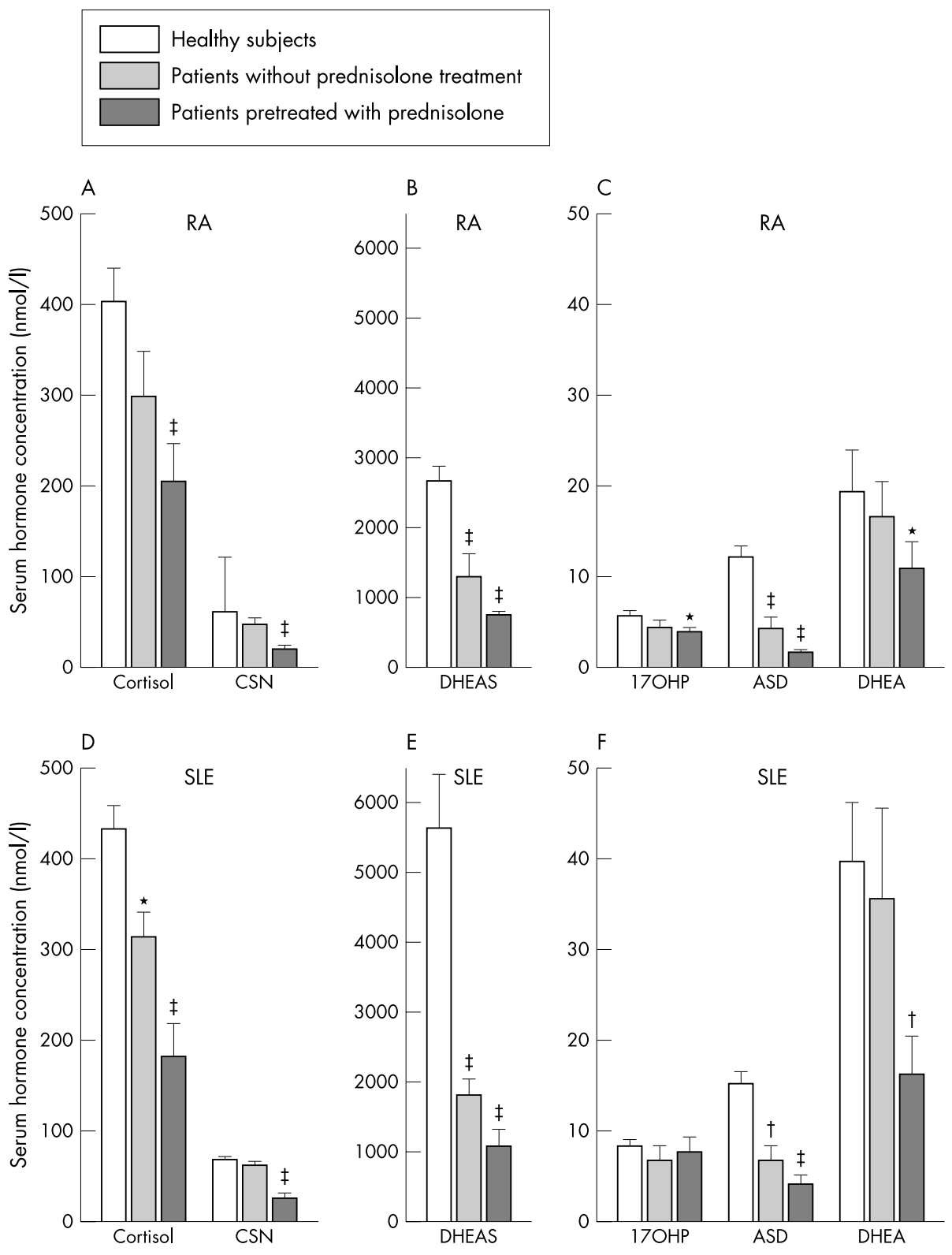

Figure 2 Serum hormone concentration of adrenal steroid hormones. (A-C) Data of patients with RA; (D-F) results of patients with SLE. Data are given as means (SEM). ${ }^{*} \mathrm{p}<0.05 ; \mathrm{tp}<0.005 ; \mathrm{t}<<0.001$ for the comparison of the respective group with HS. CSN, cortisone; DHEAS, DHEA sulphate; 17OHP, 17 hydroxyprogesterone; ASD, androstenedione; DHEA, dehydroepiandrosterone. 
lower or were significantly lower than in HS (fig 5). Interestingly, clearance of androstenedione tended to be increased or was significantly increased in both disease groups in comparison with HS (fig 5). No differences were observed for clearance of 17OHP (fig 5). The increased clearance of cortisol in both disease groups with prednisolone pretreated patients is most likely due to the erroneous detection of urine cortisol as mentioned above. In addition, no differences for cortisone clearance were found between HS and patients groups.

\section{Proteinuria and urinary hormones}

Table 3 demonstrates the frequencies of different types of proteinuria in HS, patients with RA, and patients with SLE. If we separate patients with RA and SLE according to proteinuria into two different groups, with (all types) and without proteinuria, then creatinine clearance between the groups was not significantly different. Furthermore, they did not differ with respect to measured serum, plasma, or urinary levels of hormones or parameters of hormone excretion.
Thus, the presented forms of proteinuria led to only mild deterioration of renal function.

\section{DISCUSSION}

Low serum levels of adrenal androgens and inadequately low serum cortisol in chronic inflammatory disease are thought to be caused by (a) increased renal excretion of steroid hormones; $(b)$ increased conversion or conjugation to downstream hormones such as cortisone (upstream are 17OHP and cortisol, see fig l) or oestrogens (upstream are DHEA and androstenedione); and $(c)$ inadequate adrenal production or secretion of these hormones. This study demonstrates that increased renal clearance and daily excretion of these hormones are not a likely reason for this phenomenon in the tested chronic inflammatory diseases. It is confirmed that DHEAS is the major excreted steroid hormone in both disease groups and HS. Its excretion is 10 to 1000 times higher than that of other measured steroid hormones. The urinary concentration directly depends on the available serum concentration, which is significantly higher in HS than in
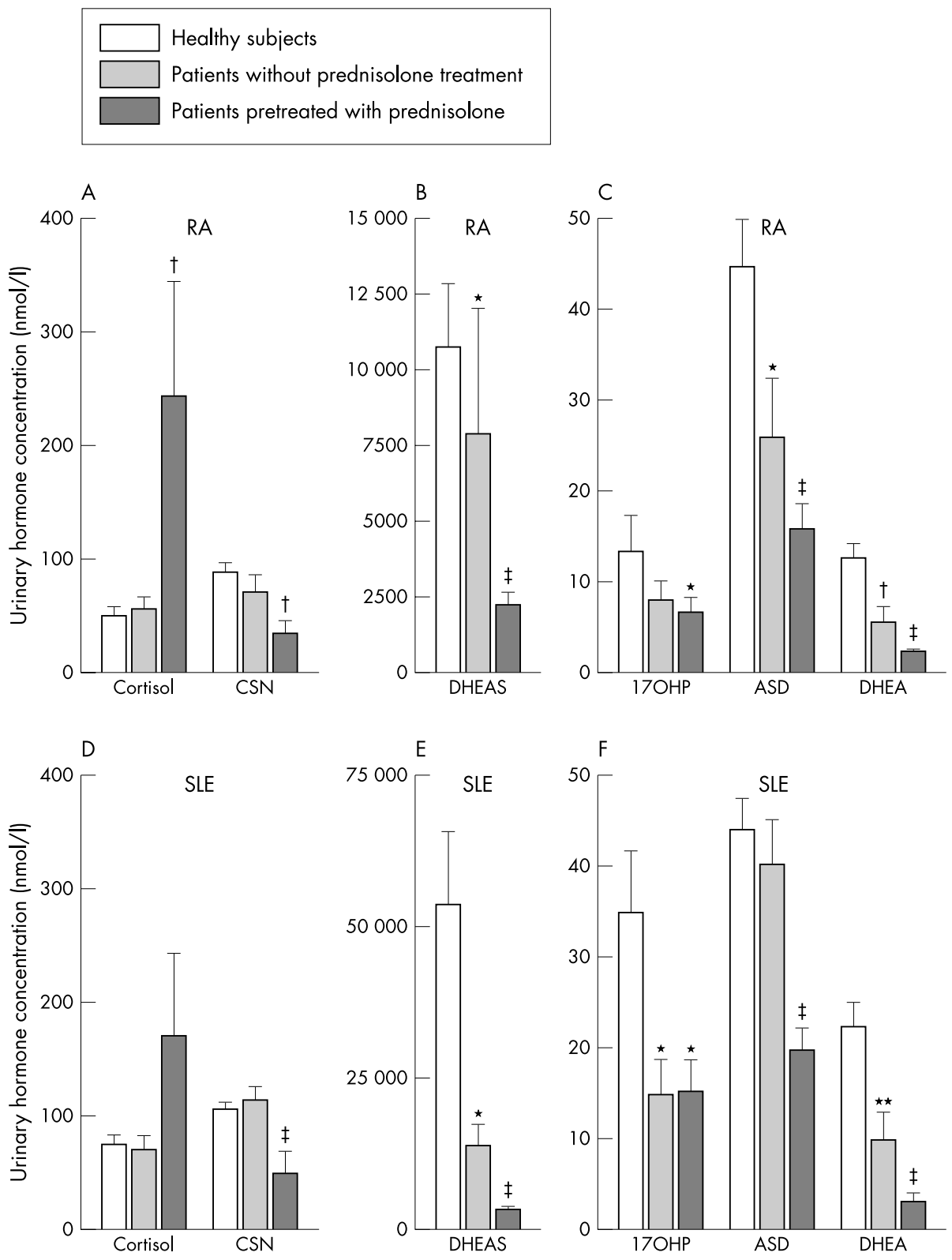

Figure 3 Urinary hormone concentration of adrenal steroid hormones. (A-C) Data of patients with RA; (D-F) results of patients with SLE. Data are given as means (SEM). ${ }^{*} \mathrm{p}<0.05 ;{ }^{* *} \mathrm{p}<0.01 ; \mathrm{\dagger p}<0.005$ $\neq p<0.001$ for the comparison of the respective group with HS. For abbreviations see the legend to fig 2 . 

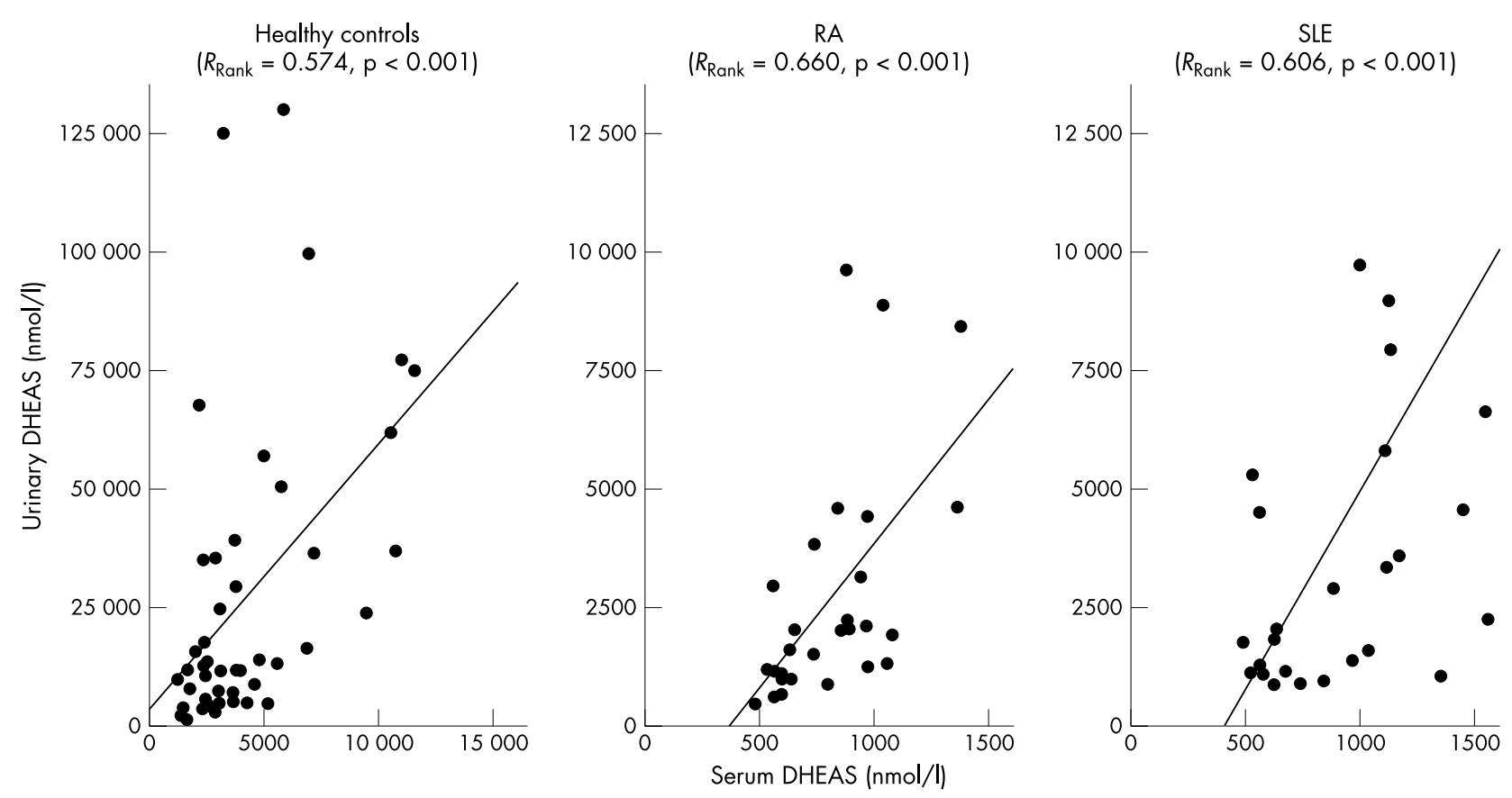

Figure 4 Interrelation between serum DHEAS and urinary DHEAS in HS, patients with RA, and patients with SLE, including those with prednisolone treatment. The $x$ axis and the $y$ axis were adjusted to the different numerical levels because the HS had clearly higher serum and urine concentrations than both patient groups. The panels include the linear regression line, the Spearman rank correlation coefficient, and the respective $p$ value.

patients with RA and SLE. Thus, the decrease of serum DHEAS in these two chronic inflammatory diseases is not due to exaggerated renal clearance and daily loss. Similarly, an increased renal clearance and excretion is not the reason for the loss of other measured steroid hormones. The slightly increased clearance for androstenedione in both disease groups in patients with and without prednisolone treatment is most probably not an indication of an increased loss of this hormone because the absolute molar amount of androstenedione is certainly not increased in patients as compared with age matched and sex matched HS (table 2). These results corroborate a recent study which looked at the profile of disappearance of total cortisol from plasma. ${ }^{34}$ Rovensky et al suggested that alterations in cortisol clearance are not likely to have a role in cortisol availability in patients with RA.

In HS and in patients with RA and SLE, serum levels of downstream cortisone are lower than those of cortisol (and urinary cortisone excretion is also lower than urinary cortisol excretion). Furthermore, serum levels of oestrogens are also 5-10 times lower than upstream androstenedione. ${ }^{35}$ These facts do not stimulate the belief that increased peripheral conversion of either cortisol to cortisone or DHEA/androstenedione to oestrogens may be an important reason for low serum levels of these hormones. Nevertheless, we do not

Table 2 Renal hormone excretion in nmol/day. Values are data of patients with and without prednisolone treatment. Patients with RA and SLE should not be compared owing to their different mean age

\begin{tabular}{|c|c|c|c|}
\hline \multirow[b]{2}{*}{ Hormone (nmol/day) } & \multicolumn{2}{|l|}{ Patient subgroup } & \multirow[b]{2}{*}{ Healthy controls* } \\
\hline & With prednisolone & Without prednisolone & \\
\hline \multicolumn{4}{|l|}{ Rheumatoid arthritis } \\
\hline Dehydroepiandrosterone & $4.9(1.0)$ & $10.1(3.3) \S$ & $25.8(4.0)$ \\
\hline Dehydroepiandrosterone sulphate & $4316(1257)$ & $12912(7876) \S$ & $20452(3574)$ \\
\hline Androstenedione & $26.8(5.3)$ & $39.1(10.8) \S$ & $104.0(20.5)$ \\
\hline 17-Hydroxyprogesterone & $9.9(1.8) \ddagger$ & $11.8(3.1) \dagger$ & $21.0(4.0)$ \\
\hline Cortisone $^{\star \star}$ & $60.4(19.7)$ & $106.9(22.6) \dagger$ & $177.2(15.2)$ \\
\hline Cortisol & $404.1(173.4) \dagger$ & $80.0(16.4)$ & $93.0(9.8)$ \\
\hline \multicolumn{4}{|l|}{ Systemic lupus erythematosus } \\
\hline Dehydroepiandrosterone & $5.3(1.2)$ & $17.0(4.1) \dagger$ & $37.9(4.2)$ \\
\hline Dehydroepiandrosterone sulphate & $6649(1562)$ & $23833(6301) \dagger$ & 108414 (28962) \\
\hline Androstenedione & $39.4(6.4)$ & $72.9(7.6)$ & $74.9(5.4)$ \\
\hline 17-Hydroxyprogesterone & $34.0(8.9)$ & $26.0(5.2)$ & $44.8(6.4)$ \\
\hline Cortisone & $64.6(17.5)$ & 213.2 (19.9) & $181.1(10.2)$ \\
\hline Cortisol & $325.7(148.0)$ & $125.8(21.5)$ & $115.0(9.2)$ \\
\hline
\end{tabular}

Data are given as means (SEM).

*Data of healthy controls were not stratified because, for age and sex, the entire control group matched the respective patient subgroups. ${ }^{* *}$ In the subgroup of patients with prior prednisolone treatment, two outliers with 1232 and $2295 \mathrm{nmol} /$ day were excluded from the analysis, which did not change the statistical comparison due to the non-parametric test.

$\mp p<0.05, \mp p<0.01, \S p<0.005, \uparrow p<0.001$ for the comparison versus healthy controls. 

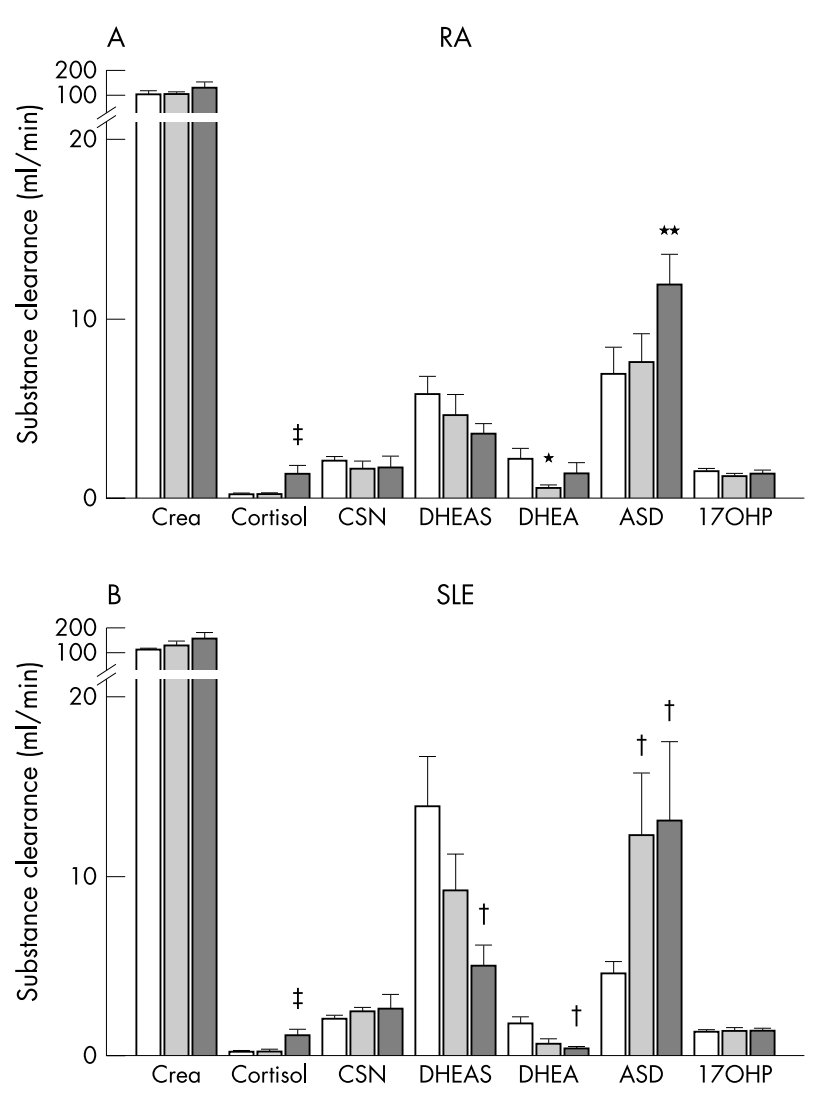

Figure 5 Substance clearance of adrenal steroid hormones. (A) Data of patients with RA; (B) results of patients with SLE. Open bars denote healthy subjects, light grey bars represent patients without prednisolone treatment, and dark grey bars demonstrate data of prednisolone pretreated patients. Data are given as means (SEM). ${ }^{*} \mathrm{p}<0.05$; ${ }^{* *} \mathrm{p}<0.01 ; \mathrm{tp}<0.005 ; \mathrm{p}<0.001$ for the comparison of the respective group versus $\mathrm{HS}$. Crea, creatinine; for other abbreviations see the legend to fig 2,

know exactly all the pathways to downstream hormones such as 7-hydroxylated, 16-hydroxylated, and 19-hydroxylated steroid hormones as well as pathways to conjugated hormones. Steroid hormones such as cortisol, DHEA, and androstenedione are probably converted in the peripheral tissue, particularly in synoviocytes of inflamed tissue. ${ }^{36}$ In this latter study, we were able to demonstrate that conversion to oestrogens is increased. Because nobody has ever measured the mentioned hydroxylated hormones in serum and urine of patients with chronic inflammatory diseases, the question of exaggerated conversion of steroid hormones is still a matter of debate.

Finally, the question of inadequate production or secretion of adrenal steroid hormones has been examined by in vitro experiments. Results of studies with adrenocortical cells demonstrate that proinflammatory cytokines such as tumour necrosis factor (TNF) (not interleukin (IL)6) inhibit important enzyme steps of steroidogenesis (fig 1$)^{37}$ (reviewed by Judd et $a l^{38}$ ). Thus, TNF may also be an inhibitor of steroidogenesis in chronic inflammatory diseases. In the current study, in three patients with RA with prednisolone pretreatment and in three patients with RA without prior prednisolone, anti-TNF treatment did not influence the presented results, which is probably owing to the small number of patients receiving this particular treatment (data were not shown). In a recent long term follow up study in 19 patients with RA, we demonstrated that treatment with an anti-TNF antibody can increase the serum levels of androstenedione in relation to cortisol and 17OHP. ${ }^{39}$ These factors
Table 3 Proteinuria in healthy subjects and patients with RA and SLE. The following proteins represent the different types of proteinuria: transferrin for "selective glomerular"; transferrin+lgG for "non-selective glomerular"; $\alpha_{1}$-microglobulin for "tubular"; $\alpha_{1}$ microglobulin+transferrin for "selective glomerular+ tubular"; $\alpha_{1}$-microglobulin+transferrin+lgG for "nonselective glomerular+tubular"

\begin{tabular}{|c|c|c|c|}
\hline & RA & SLE & $\begin{array}{l}\text { Healthy } \\
\text { subjects }\end{array}$ \\
\hline \multicolumn{4}{|c|}{ Comparison of patients with RA and healthy subjects } \\
\hline Normal function & 24 & & 22 \\
\hline Selective glomerular & 4 & & 1 \\
\hline Non-selective glomerular & 1 & & 0 \\
\hline Tubular & 0 & & 0 \\
\hline Mixed (selective glomerular+tubular) & 1 & & 0 \\
\hline Mixed (non-selective glomerular+tubular) & 0 & & 0 \\
\hline \multicolumn{4}{|c|}{ Comparison of patients with SLE and healthy subjects } \\
\hline Normal function & & 16 & 41 \\
\hline Selective glomerular & & 8 & 1 \\
\hline Non-selective glomerular & & 1 & 0 \\
\hline Tubular & & 0 & 0 \\
\hline Mixed (selective glomerular+tubular) & & 2 & 0 \\
\hline Mixed (non-selective glomerular+tubular) & & 4 & 0 \\
\hline
\end{tabular}

indicate that inadequate production of cortisol, DHEA, DHEAS, and androstenedione may be due to inflammation induced reduction of adrenal steroidogenesis. In addition, inadequately low plasma levels of ACTH in relation to serum TNF or IL6 levels have been described in chronic inflammatory diseases such as RA and reactive arthritis. ${ }^{13}$ Thus, the most important stimulus from the pituitary gland may fail to stimulate an adequate adrenal response during systemic inflammation.

In conclusion, in patients with RA and SLE, independently of corticosteroid treatment, the measured excretion of adrenal steroid hormone is not increased compared with that of HS. In contrast, the total excreted amount of DHEAS, DHEA, and androstenedione is clearly decreased or is similar to that of HS. Thus, renal clearance and daily loss of these hormones is not a likely cause for the lower serum levels of these adrenal androgens and the inadequately low serum levels of cortisol in relation to systemic inflammation.

\section{ACKNOWLEDGEMENTS}

Parts of this study were funded by the Deutsche Forschungsgemeinschaft (Str 511/10-1, SCHM 1611/1-1) and by the respective institutions.

\section{Authors' affiliations}

R H Straub, C Weidler, B Demmel, J Schölmerich, J Schedel, Laboratory of Neuroendocrinoimmunology, Department of Internal Medicine I, University Hospital Regensburg, D-93042 Regensburg, Germany M Herrmann, Central Laboratory, University Hospital of Saarland, 66421 Homburg/Saar, Germany

F Kees, Department of Pharmacology, Institute of Pharmacy, University Regensburg, 93053 Regensburg, Germany

M Schmidt, Department of Biochemistry, University Hospital Jena, 07740 Jena, Germany

\section{REFERENCES}

1 Reincke M, Heppner C, Petzke F, Allolio B, Arlt W, Mbulamberi D, et al. Impairment of adrenocortical function associated with increased plasma tumor necrosis factor-alpha and interleukin-6 concentrations in African trypanosomiasis. Neuroimmunomodulation 1994;1:14-22.

2 Johnson EO, Vlachoyiannopoulos PG, Skopouli FN, Tzioufas AG, Moutsopoulos HM. Hypofunction of the stress axis in Siögren's syndrome. J Rheumatol 1998;25:1508-14. 
3 Zietz B, Reber T, Oertel M, Glück T, Schölmerich J, Straub RH. Altered function of the hypothalamic stress axes in patients with moderately active systemic lupus erythematosus. II. Dissociation between androstenedione, cortisol, or dehydroepiandrosterone and interleukin 6 or tumor necrosis factor. J Rheumatol 2000;27:911-18.

4 van den Brink HR, Blankenstein MA, Koppeschaar HP, Bijlsma JW. Influence of disease activity on steroid hormone levels in peripheral blood of patients with rheumatoid arthritis. Clin Exp Rheumatol 1993;1 1:649-52.

5 Hall J, Morand EF, Medbak S, Zaman M, Perry L, Goulding NJ, et al. Abnormal hypothalamic-pituitary-adrenal axis function in rheumatoid arthritis. Effects of nonsteroidal antiinflammatory drugs and water immersion. Arthritis Rheum 1994;37:1132-7.

6 Gudbjornsson B, Skogseid B, Oberg K, Wide L, Hallgren R. Intact adrenocorticotropic hormone secretion but impaired cortisol response in patients with active rheumatoid arthritis. Effect of glucocorticoids. J Rheumatol 1996;23:596-602.

7 Templ E, Koeller M, Riedl M, Wagner O, Graninger W, Luger A. Anterior pituitary function in patients with newly diagnosed rheumatoid arthritis. Br J Rheumatol 1996;35:350-6.

8 Crofford U, Kalogeras KT, Mastorakos G, Magiakou MA, Wells J, Kanik KS, et al. Circadian relationships between interleukin (IL)- 6 and hypothalamicpituitary-adrenal axis hormones: failure of IL-6 to cause sustained hypercortisolism in patients with early untreated rheumatoid arthritis. J Clin Endocrinol Metab 1997:82:1279-83.

9 Cutolo M, Foppiani L, Prete C, Ballarino P, Sulli A, Villaggio B, et al. Hypothalamic-pituitary-adrenocortical axis function in premenopausal women with rheumatoid arthritis not treated with glucocorticoids. J Rheumatol 1999:26:282-8.

10 Gutierrez MA, Garcia ME, Rodriguez JA, Mardonez G, Jacobelli S, Rivero S. Hypothalamic-pituitary-adrenal axis function in patients with active rheumatoid arthritis: a controlled study using insulin hypoglycemia stress test and prolactin stimulation. J Rheumatol 1999:26:277-81.

11 Demir H, Kelestimur F, Tunc M, Kirnap M, Ozugul Y. Hypothalamo-pituitaryadrenal axis and growth hormone axis in patients with rheumatoid arthritis. Scand J Rheumatol 1999;28:41-6.

12 Kanik KS, Chrousos GP, Schumacher HR, Crane ML, Yarboro CH, Wilder RL. Adrenocorticotropin, glucocorticoid, and androgen secretion in patients with new onset synovitis/rheumatoid arthritis: relations with indices of inflammation. J Clin Endocrinol Metab 2000;85:1461-6.

13 Straub RH, Paimela L, Peltomaa R, Schölmerich J, Leirisalo-Repo M. Inadequately low serum levels of steroid hormones in relation to IL-6 and TNF in untreated patients with early rheumatoid arthritis and reactive arthritis. Arthritis Rheum 2002;46:654-62.

14 Feher GK, Feher T, Zahumenszky Z. Study on the inactivation mechanism of androgens in rheumatoid arthritis: excretory rate of free and conjugated 17 ketosteroids. Endokrinologie 1979;73:167-72.

15 Masi AT, Josipovic DB, Jefferson WE. Low adrenal androgenic-anabolic steroids in women with rheumatoid arthritis (RA): gas-liquid chromatographic studies of RA patients and matched normal control women indicating decreased 11-deoxy-17-ketosteroid excretion. Semin Arthritis Rheum 1984; 14:1-23.

16 Cutolo M, Balleari E, Giusti M, Monachesi M, Accardo S. Sex hormone status of male patients with rheumatoid arthritis: evidence of low serum concentrations of testosterone at baseline and after human chorionic gonadotropin stimulation. Arthritis Rheum 1988;31:1314-17.

17 Sambrook PN, Eisman JA, Champion GD, Pocock NA. Sex hormone status and osteoporosis in postmenopausal women with rheumatoid arthritis. Arthritis Rheum 1988;31:973-8.

18 Deighton CM, Watson MJ, Walker DJ. Sex hormones in postmenopausal HLA-identical rheumatoid arthritis discordant sibling pairs. J Rheumatol 1992; 19:1663-7.

19 Hedman M, Nilsson E, de la Torre B. Low blood and synovial fluid levels of sulpho-conjugated steroids in rheumatoid arthritis. Clin Exp Rheumatol 1992;10:25-30.

20 Valentino R, Savastano S, Tommaselli AP, Riccio A, Mariniello P, Pronesti G, et al. Hormonal pattern in women affected by rheumatoid arthritis. J Endocrinol Invest 1993;16:619-24.
21 Mateo L, Nolla JM, Bonnin MR, Navarro MA, Roig-Escofet D. Sex hormone status and bone mineral density in men with rheumatoid arthritis. J Rheumatol 1995;22:1455-60.

22 Mirone L, Altomonte L, D'Agostino P, Zoli A, Barini A, Magaro M. A study of serum androgen and cortisol levels in female patients with rheumatoid arthritis. Correlation with disease activity. Clin Rheumatol 1996;15:15-19.

23 Straub RH, Cutolo M. Involvement of the hypothalamic-pituitary-adrenal/ gonadal axis and the peripheral nervous system in rheumatoid arthritis: viewpoint based on a systemic pathogenetic role. Arthritis Rheum 2001;44:493-507.

24 van Vollenhoven RF, Engleman EG, McGuire JL. Dehydroepiandrosterone in systemic lupus erythematosus. Results of a double-blind, placebo-controlled, randomized clinical trial. Arthritis Rheum 1995;38:1826-31.

25 Chang DM, Lan JL, Lin HY, Luo SF. Dehydroepiandrosterone treatment of women with mild-to-moderate systemic lupus erythematosus: a multicenter randomized, double-blind, placebo-controlled trial. Arthritis Rheum 2002;46:2924-7

26 Petri MA, Lahita RG, van Vollenhoven RF, Merrill JT, Schiff M, Ginzler EM, et al. Effects of prasterone on corticosteroid requirements of women with systemic lupus erythematosus: a double-blind, randomized, placebocontrolled trial. Arthritis Rheum 2002;46:1820-9.

27 Andus T, Klebl F, Rogler G, Bregenzer N, Schölmerich J, Straub RH. Patients with refractory Crohn's disease or ulcerative colitis respond to dehydroepiandrosterone: a pilot study. Aliment Pharmacol Ther 2003;17:409-14

28 Arnett FC, Edworthy SM, Bloch DA, McShane DJ, Fries JF, Cooper NS, et al. The American Rheumatism Association 1987 revised criteria for the classification of rheumatoid arthritis. Arthritis Rheum 1988;31:315-24.

29 Tan EM, Cohen AS, Fries JF, Masi AT, McShane DJ, Rothfield NF, et al. The 1982 revised criteria for the classification of systemic lupus erythematosus. Arthritis Rheum 1982;25:1271-7.

30 Straub RH, Konecna L, Hrach S, Rothe G, Kreutz M, Schölmerich J, et al. Serum dehydroepiandrosterone (DHEA) and DHEA sulfate are negatively correlated with serum interleukin-6 (IL-6), and DHEA inhibits IL-6 secretion from mononuclear cells in man in vitro: possible link between endocrinosenescence and immunosenescence. J Clin Endocrinol Metab 1998:83:2012-17.

31 Ligthart GJ, Corberand JX, Fournier C, Galanaud P, Hijmans W, Kennes B, et al. Admission criteria for immunogerontological studies in man: the SENIEUR protocol. Mech Ageing Dev 1984;28:47-55.

32 Solerte SB, Severgnini S, Locatelli M, Cerutti N, Rondanelli M, Netti MA, et al. Nephelometry in the clinical assessment of glomerular proteinuria and tubular function in diabetic nephropathy. Clin Nephrol 1997;48:151-8.

33 Santos-Montes A, Gonzalo-Lumbreras R, Izquierdo-Hornillos R. Simultaneous determination of cortisol and cortisone in urine by reversed-phase highperformance liquid chromatography. Clinical and doping contro applications. J Chromatogr B Biomed Appl 1995:673:27-33.

34 Rovensky J, Imrich R, Koska J, Kovalancik M, Killinger Z, Payer J, et al. Cortisol elimimation from plasma in premenopausal women with rheumatoid arthritis. Ann Rheum Dis 2003;62:674-6.

35 Greenspan FS. Basic and clinical endocrinology. East Norwalk: Appleton and Lange, 1991.

36 Castagnetta LA, Carruba G, Granata OM, Stefano R, Miele M, Schmidt M et al. Increased estrogen formation and estrogen to androgen ratio in the synovial fluid of patients with rheumatoid arthritis. J Rheumatol 2003:30:2597-605

37 Jäättelä M, Ilvesmaki V, Voutilainen R, Stenman UH, Saksela E. Tumor necrosis factor as a potent inhibitor of adrenocorticotropin-induced cortisol production and steroidogenic P450 enzyme gene expression in cultured human fetal adrenal cells. Endocrinology 1991;128:623-9.

38 Judd AM, Call GB, Barney M, Mcllmoil CJ, Balls AG, Adams A, et al. Possible function of IL- 6 and TNF as intraadrenal factors in the regulation of adrenal steroid secretion. Ann N Y Acad Sci 2000;917:628-37.

39 Straub RH, Pongratz G, Schölmerich J, Kees F, Schaible TF, Antoni C, et al. Long-term anti-tumor necrosis factor antibody therapy in rheumatoid arthritis patients sensitizes the pituitary gland and favors adrenal androgen secretion. Arthritis Rheum 2003;48:1504-12. 